\title{
Editorial
}

\section{Retailer power, pricing and premium brand}

\section{OFFICE OF FAIR TRADING ENQUIRY}

The power of the major supermarkets has greatly increased over the past twenty years. Their share of the packaged grocery market has gone up from under 50 per cent in 1978 to almost 80 per cent at the present time (on Taylor Nelson Sofres definitions). Within that growth, the share of the top three groups has doubled. These developments have understandably caused disquiet in a number of quarters, culminating in the recent OFT investigation into the activities of the leading supermarket chains. No doubt this initiative will be applauded by those competitors and suppliers of the supermarkets who feel they are being unfairly treated.

It is not appropriate to deal here with the broad canvas of the OFT enquiry. However it is important to examine the criticisms of supermarkets made in the run-up to the enquiry, distinguishing between the serious competitive issues raised by supermarket power and the newsworthy but factually dubious charges which have been advanced, often stridently, by some journalist and politicians.

For instance, 'evidence' that consumers in the UK pay significantly more for their food than those in most European countries is based on the use of quite atypical shopping baskets as a basis for comparison, as well as the omission of any consideration of the role of own label in this country. A good although not conclusive case, based on much more reliable figures of share of expenditure going on food in different countries, would actually suggest that food prices in the UK were lower than those in nearly all European countries. Similarly, accusations that supermarkets do not compete against each other and are destroying town centre shopping tend to be either misleading or to contradict other parts of the indictment.

Some new information relating to the clustering of stores is of some relevance here. For example, 90 per cent of Sainsbury stores are within three kilometres of a store from one of the other four major retailers, while more than 80 per cent of consumers are within five kilometres of at least two major retail outlets. Given the increase in car ownership, it is likely that most consumers now have a greater choice of grocery shopping than ever before.

There remains, however, the serious question of whether the ever growing power of supermarkets is used extortionately against their suppliers and in particular whether the unfair favouring of own label inevitably leads to the decline and eventual extinction of the premium brand. A great deal of accurate information is available here and is worth considering in some detail.

\section{Own label and its impact on premium brands}

Not so long ago, the media devoted many column inches to the rapid growth of own label in the FMCG sector and how it spelt out gloom, doom and even death for the premium brand. More recently there has been a rush to the other extreme based on the latest figures showing a plateau of ownlabel share of trade. As usual, neither of these extremes are accurate. It is true that 
there are now reasons for believing that the main engines of growth for own label are starting to slow down, but there have been plateaus in the own-label growth curve before which has subsequently resumed its upward path. The likelihood is that the own label share of trade is moving towards its asymptote but may still have some little way to go; one guestimate has put the ceiling at about 45 per cent of consumers expenditure compared to 41 per cent at the present time.

But these are average levels and enormous differences occur between individual product fields. Even within the same food sector, interesting differences can be observed associated with the nature of the product, the degree of innovation and the impact of advertising and marketing. For example, in the soft drinks sector, own label continues on its merry way (now over 80 per cent) for canned and bottled lemonade but it has only achieved about 15 per cent in the canned colas' market, a reduction if anything on the levels it achieved two or three years ago.

In most product fields, very significant price differentials exist between the ownlabel offering and the premium brand. Typically, this is of the order of 25 per cent for the standard own label product, with much larger differences for the budget own-label offering. In the occasional price war that occurs, the price differentials rise to ridiculous levels - witness the $3 p$ can of baked beans and, more recently, the $7 p$ wrapped loaf. And yet, despite these enormous price differences most, though by no means all, premium brands have shown great resilience.

Taylor Nelson Sofres analysed 26 major product fields over the period from the mid1970 s to the present time and found that in 19 of these, the brand leader in 1975 was still the brand leader today and in the majority of these cases had actually increased its brand share. The number two brand in these markets showed reasonable stability though not as good as the brand leaders. It was the very small brands that were the main casualties of the success of own label.

\section{CONCLUSION}

Since power should bring with it responsibility, it is right that the competitive practices of the increasingly dominant supermarket chains should be kept under scrutiny to ensure that responsibility is exercised. However, a more balanced scrutiny of the present position than has been offered by most of the press would suggest that consumers are doing reasonably well in the present grocery market, and even the brand manufacturers can work out an acceptable modus vivendi with the retailers as long as they nourish their brands properly.

Stephan F. Buck Editorial Board 